\title{
Expression and clinical significance of girdin in gastric cancer
}

\author{
CAIHUA WANG ${ }^{1 *}$, JIE LIN $^{2 *}$, LURONG $\mathrm{LI}^{2}$ and YUN WANG ${ }^{2}$ \\ ${ }^{1}$ Department of Gastroenterology, Guanghe Chinese and Western Medicine Hospital, Zhangjiagang, Jiangsu 215633; \\ ${ }^{2}$ Institute of Digestive Endoscopy and Medical Center for Digestive Diseases, \\ The Second Affiliated Hospital of Nanjing Medical University, Nanjing, Jiangsu 210011, P.R. China
}

Received October 24, 2013; Accepted February 3, 2014

DOI: $10.3892 / \mathrm{mco} .2014 .265$

\begin{abstract}
Gastric cancer is one of the most common malignant tumors and the second leading cause of cancer-related mortality. Elucidating the molecular mechanism underlying the development of gastric cancer is crucial in identifying gastric cancer-susceptible populations, screening for tumor markers and in the application of gene therapy. This study was conducted to investigate girdin expression in gastric cancer and para-cancer tissues and to elucidate the role of girdin in the development of gastric cancer. Tissue microarray and streptavidin-peroxidase immunohistochemical staining were used to detect girdin expression in 105 gastric cancer and 72 para-cancer tissue samples. Analyses of the patients' clinical and pathological data were also performed. The expression ratio of girdin was $40.0 \%$ in gastric cancer and $11.1 \%$ in the para-cancer tissues and the difference was statistically significant $(\mathrm{P}<0.05)$. Girdin expression was found to be positively correlated $(\mathrm{P}<0.05)$ with tumor invasion depth and lymph node metastasis, while no significant associations were found between girdin expression and gender, age, tumor size, pathological grade and clinical stage $(\mathrm{P}>0.05)$. In conclusion, the upregulation of girdin expression in gastric cancer may contribute to tumor metastasis and cancer development, suggesting that girdin may be a novel indicator for evaluating lymph node metastasis and gastric cancer outcome.
\end{abstract}

\section{Introduction}

Gastric cancer is one of the most common malignant tumors and the second leading cause of cancer-related mortality (1).

Correspondence to: Dr Yun Wang, Institute of Digestive Endoscopy and Medical Center for Digestive Diseases, The Second Affiliated Hospital of Nanjing Medical University, 121 Jiangjiayuan Road, Nanjing, Jiangsu 210011, P.R. China E-mail: hongwangyun@hotmail.com

*Contributed equally

Key words: gastric cancer, girdin expression, tissue microarray, metastasis
Elucidating the molecular mechanism underlying the development of gastric cancer is crucial in identifying gastric cancer-susceptible populations, screening for tumor markers and in the application of gene therapy. Girdin is an actin-binding protein that contains an actin-binding domain, a membrane-binding domain and an Akt phosphorylation site, first identified by a group of Japanese scholars in 2005 (2-4). Girdin plays an essential role in promoting cell proliferation, which is a critical factor in various physiological processes, including embryonic development, inflammation, angiogenesis and tumor development $(5,6)$. The role of girdin in the development of breast and colorectal cancer was recently confirmed (7-9); however, the association between girdin and gastric cancer is yet to be fully elucidated. This study aimed to determine girdin expression in gastric cancer and para-cancer tissues using immunohistochemical detection and to investigate the association between girdin expression and the clinicopathological characteristics of gastric cancer, as well as the function of girdin in gastric cancer development and progression.

\section{Materials and methods}

Clinical data collection. In this study, we used 10x16 gastric cancer tissue microarrays (FM-S4006-1; Outdo Biotechnology, Shanghai, China) with a diameter of $1.5 \mathrm{~mm}$ and a thickness of $4 \mu \mathrm{m}$ that were prepared according to a standard method. The integrity of each chip was $>95 \%$. A total of 105 gastric cancer patients (67 men and 38 women) with a median age of 60 years (range, 30-84 years) were included in this study. According to the tumor differentiation grading system recommended by the World Health Organization in 2000, 99 cases were determined as poorly-differentiated adenocarcinomas and 6 cases were determined as well-differentiated adenocarcinomas. According to the tumor-node-metastasis cancer staging system recommended by the International Union Against Cancer in 2002, 13, 17, 79 and 7 cases were determined as stage I, II, III and IV cancer, respectively.

Experimental reagents. The rabbit anti-human girdin monoclonal antibody and corresponding secondary donkey anti-rabbit antibody were purchased from Santa Cruz Biotechnology, Inc. (sc-22218 and 711-065-152; Santa Cruz, CA, USA). The antibodies were preserved at $-20^{\circ} \mathrm{C}$ and the working 
Table I. Girdin expression in gastric cancer and para-cancer tissues.

Girdin expression

\begin{tabular}{lccccc}
\cline { 3 - 5 } Location & Cases & Positive & Negative & Expression ratio (\%) & P-value \\
\hline Gastric cancer & 105 & 42 & 63 & 40.0 & $<0.001$ \\
Para-cancer tissues & 72 & 8 & 64 & 11.1 & \\
\hline
\end{tabular}
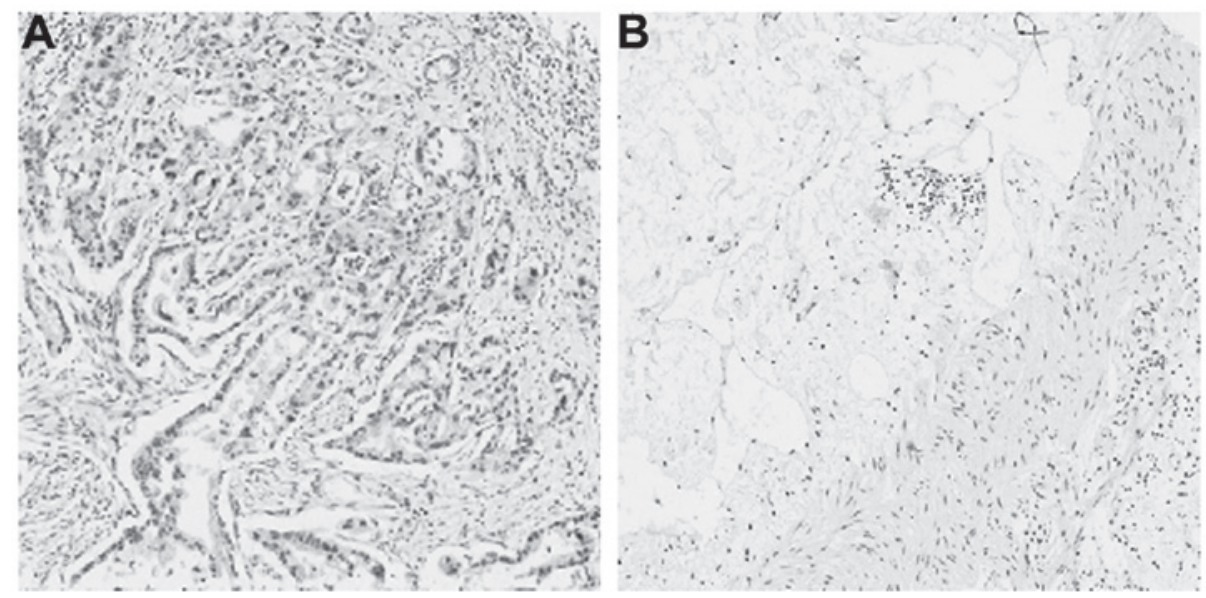

Figure 1. Detection of girdin expression in gastric cancer and para-cancer tissues using streptavidin-peroxidase immunohistochemical staining (magnification, $\mathrm{x} 200$ ). (A) Positive expression of girdin in cancer tissues. (B) Negative expression of girdin in para-cancer tissues.

concentration of the primary antibody was $4 \mu \mathrm{g} / \mathrm{ml}$. The streptavidin-peroxidase (S-P) immunohistochemical staining hypersensitivity kit was purchased from Dako Japan Inc. (Kyoto, Japan).

Experimental methods. S-P immunohistochemical staining was used to detect the expression level of girdin. Known positive tissue sections and phosphate-buffered saline (instead of primary antibody) were used as positive and negative controls, respectively. The staining was performed according to the instructions provided by the manufacturer. The staining intensity of the cells was graded as follows: 0 , negative; 1 , light yellow granules; 2, deep yellow granules; and 3, brown granules points. Grading was performed as follows: 0 , positive cell ratio $\leq 5 \% ; 1,5 \%<$ positive cell ratio $\leq 25 \% ; 2,25 \%<$ positive cell ratio $\leq 50 \% ; 3,50 \%<$ positive cell ratio $\leq 75 \%$; and $4,75 \%<$ positive cell ratio $\leq 100 \%$ points.

The final point score for girdin expression was determined through the multiplication of the points for staining intensity by the points for positive cell ratio. The girdin expression levels were graded as follows: -, points $\leq 4 ;+, 4<$ points $\leq 8$; ,$++ 8<$ points $\leq 12$; and +++ , points $>12$. Grade - was determined as girdin-negative, whereas,+++ and +++ were determined as girdin-positive.

Statistical analyses. Data analyses were performed using SPSS software, version 13.0 (SPSS Inc., Chicago, IL, USA). The $\chi^{2}$ test was used to evaluate the girdin expression differences between gastric cancer and para-cancer tissues and the association between girdin expression and other clinicopathological parameters, including gender, age, clinical stage, histological grade, lymph node metastasis, tumor size and depth of invasion.

\section{Results}

Quality control of tissue microarray. Following immunohistochemical staining, tissue samples with defects or poor staining were excluded, leaving a total of 177 samples, including 105 gastric cancer and 72 gastric para-cancer tissue samples.

Assessment of girdin expression. Of the 105 gastric cancer cases, 42 (44.4\%) exhibited positive girdin expression (mainly in the cytoplasm) and $72(55.6 \%)$ exhibited negative girdin expression. Of the 72 para-cancer tissue samples, only 8 (11.1\%) exhibited positive girdin expression. The difference in girdin expression between gastric cancer and para-cancer tissues was found to be statistically significant $(\mathrm{P}<0.05)$. The results are shown in Fig. 1 and Table I.

Association between girdin expression and other clinicopathological parameters. There was no significant association between girdin-positive expression and gender, age, tumor size, tumor location, clinical stage and histological grade $(\mathrm{P}>0.05)$. However, girdin expression exhibited a significant positive correlation with tumor invasion depth and lymph node metastasis $(\mathrm{P}<0.05)$. The results are presented in Table II.

\section{Discussion}

Gastric cancer is one of the most pathogenic and lethal malignancies in China. Epidemiological studies indicated 
Table II. Association between girdin expression and other clinicopathological characteristics of gastric cancer.

Girdin expression

\begin{tabular}{|c|c|c|c|c|c|}
\hline \multirow{2}{*}{ Clinicopathological data } & \multirow{2}{*}{ Cases } & & & & \multirow{2}{*}{ P-value } \\
\hline & & Positive & Negative & Expression ratio (\%) & \\
\hline Gender & & & & & 0.115 \\
\hline Male & 67 & 23 & 44 & 34.3 & \\
\hline Female & 38 & 19 & 19 & 50.0 & \\
\hline Age (years) & & & & & 0.574 \\
\hline$\leq 60$ & 46 & 17 & 29 & 37.0 & \\
\hline$>60$ & 59 & 25 & 34 & 42.4 & \\
\hline Pathological grading & & & & & 0.822 \\
\hline Highly differentiated (I, I-II) & 6 & 3 & 3 & 50.0 & \\
\hline Moderately differentiated (II, II-III) & 46 & 19 & 27 & 41.3 & \\
\hline Poorly differentiated (III, IV) & 53 & 20 & 33 & 37.7 & \\
\hline Clinical staging & & & & & 1.000 \\
\hline Stage I+II & 30 & 12 & 18 & 40.0 & \\
\hline Stage III+IV & 75 & 30 & 45 & 40.0 & \\
\hline Depth of invasion & & & & & 0.048 \\
\hline $\mathrm{T} 1+\mathrm{T} 2$ & 18 & 4 & 14 & 22.2 & \\
\hline $\mathrm{T} 3+\mathrm{T} 4$ & 84 & 40 & 44 & 47.6 & \\
\hline Lymph node metastasis & & & & & 0.036 \\
\hline No & 21 & 4 & 17 & 19.0 & \\
\hline Yes & 84 & 37 & 47 & 44.0 & \\
\hline Tumor size $(\mathrm{cm})$ & & & & & 0.339 \\
\hline$<5$ & 54 & 24 & 30 & 44.4 & \\
\hline$\geq 5$ & 51 & 18 & 33 & 35.3 & \\
\hline
\end{tabular}

that the development of gastric cancer may be associated with various factors, such as genetic, environmental and Helicobacter pylori infection (10); however, the molecular mechanism underlying gastric cancer progression has not been fully elucidated. It was previously suggested that the development and progression of gastric cancer is a complicated process involving multiple genes, factors and stages and that different tumor-associated genes or pathways participate in the regulation of gastric cancer development (11). Girdin is an actin-binding protein located at chromosome $2 \mathrm{p} 16.1$ and was first identified by a group of Japanese scholars in 2005 . This macromolecular protein contains 1,870 amino acid residues, has an approximate molecular mass of $220-250 \mathrm{kDa}$ and interacts with Akt, Gai/s, dynamin and guanosine triphosphate hydrolase enzyme (GTPase) $(2,3)$. It was recently demonstrated that girdin is expressed by various tumor cell lines and tissues and it may promote the formation of malignant tumors (12). In a study of 180 malignant tumor tissues, Jiang et al (13) detected high expression of girdin in breast, colorectal, lung, cervical and thyroid cancer tissues. The expression ratio of girdin varied between 10 and 50\% among different types of cancer, reaching 10-35\% in invasive ductal breast carcinoma tissues. Ghosh et al (14) demonstrated that girdin could only be detected in colorectal cancer cells with high metastatic ability, such as HCT116 and DLDl cells and not in cells with low metastatic ability (HT29p and Ls174T).
Kitamura et al (5) suggested that endothelial cell-derived tumors, such as hemangioma and angiosarcoma, exhibited elevated girdin expression. Zhang et al (15) also found high levels of Akt-mediated girdin phosphorylation in human malignant glioma tissues.

Although several studies have been performed on girdin expression in a variety of cancers, the number of studies on girdin expression in gastric cancer tissues is currently limited. Our study used S-P immunohistochemical staining to assess girdin expression in gastric cancer and para-cancer tissues. The results indicated that gastric cancer tissues expressed significantly higher $(\mathrm{P}<0.05)$ levels of girdin compared to para-cancer tissues and girdin expression was found to be positively correlated $(\mathrm{P}<0.05)$ with the depth of tumor invasion and lymph node metastasis, which are two significant prognostic indicators for gastric cancer. We also demonstrated that girdin expression levels in gastric cancer samples with different invasion depth were statistically significantly different. The expression ratio of girdin was $22.2 \%$ in gastric cancers with an invasion depth of T1 and T2 and it was significantly increased to $47.6 \%$ in cancers with an invasion depth of T3 and T4. The expression ratio of girdin was $19.0 \%$ in gastric cancers without lymph node metastasis and was significantly elevated to $44.0 \%$ in cancers with lymph node metastasis. Thus, we hypothesized that increased girdin expression may be an important event during gastric cancer progression. 
In conclusion, girdin expression was found to be positively associated with the depth of invasion and lymph node metastasis. Therefore, girdin may be considered to be a novel indicator in evaluating gastric cancer metastasis and prognosis, as well as a candidate target in gastric cancer therapy. However, elucidating the molecular mechanism underlying gastric cancer induction by girdin requires further investigation.

\section{Acknowledgements}

This study was funded by grants from the Natural Science Foundation of Jiangsu Province (no. BK2012481), the Science and Technology Innovation Foundation of Nanjing Medical University (no. 2011NJMU247) and the Technology Foundation for Selected Overseas Chinese Scholars, Ministry of Personnel of China.

\section{References}

1. Jemal A, Bray F, Center MM, Ferlay J, Ward E and Forman D: Global cancer statistics. CA Cancer J Clin 61: 69-90, 2011.

2. Enomoto A, Murakami H, Asai N, et al: Akt/PKB regulates actin organization and cell motility via Girdin/APE. Dev Cell 9: 389-402, 2005

3. Enomoto A, Ping J and Takahashi M: Girdin, a novel actin-binding protein, and its family of proteins possess versatile functions in the Akt and Wnt signaling pathways. Ann NY Acad Sci 1086: 169-184, 2006.
4. Weng L, Enomoto A, Ishida-Takagishi M, Asai N and Takahashi M: Girding for migratory cues: roles of the Akt substrate Girdin in cancer progression and angiogenesis. Cancer Sci 101: 836-842, 2010.

5. Kitamura T, Asai N, Enomoto A, et al: Regulation of VEGF-mediated angiogenesis by the Akt/PKB substrate Girdin. Nat Cell Biol 10: 329-337, 2008.

6. Enomoto A, Asai N, Namba T, et al: Roles of disrupted-in-schizophrenia 1-interacting protein girdin in postnatal development of the dentate gyrus. Neuron 63: 774-787, 2009.

7. Liu C, Zhang Y, Xu H, et al: Girdin protein: a new potential distant metastasis predictor of breast cancer. Med Oncol 29: 1554-1560, 2012

8. Ling Y, Jiang P, Cui SP, et al: Clinical implications for girdin protein expression in breast cancer. Cancer Invest 29: 405-410, 2011.

9. Jun BY, Kim SW, Jung CK, et al: Expression of girdin in human colorectal cancer and its association with tumor progression. Dis Colon Rectum 56: 51-57, 2013.

10. Forte GI, Calà C, Scola L, et al: Role of environmental and genetic factor interaction in age-related disease development: the gastric cancerparadigm. Rejuvenation Res 11: 509-512, 2008.

11. Brivanlou AH and Darnell JE Jr: Signal transduction and the control of gene expression. Science 295: 813-818, 2002.

12. Ghosh P, Garcia-Marcos M and Farquhar MG: GIV/Girdin is a rheostat that fine-tunes growth factor signals during tumor progression. Cell Adh Migr 5: 237-248, 2011.

13. Jiang P, Enomoto A, Jijiwa M, et al: An actin-binding protein Girdin regulates the motility of breast cancer cells. Cancer Res 68: 1310-1318, 2008.

14. Ghosh P, Garcia-Marcos M, Bornheimer SJ and Farquhar MG: Activation of Galphai3 triggers cell migration via regulation of GIV. J Cell Biol 182: 381-393, 2008.

15. Zhang B, Gu F, She C, et al: Reduction of Akt2 inhibits migration and invasion of glioma cells. Int J Cancer 125: $585-595,2009$ 